\title{
VIEWPOINT
}

\section{Climate and cultural aspects in intensive care units}

Bertrand Guidet'1,3* and Vicente González-Romá4*

\begin{abstract}
Research carried out in the field of work and organisational psychology shows that work unit climate and culture are important determinants of work unit performance. We briefly summarise what we have learnt about the climate-performance relationship in work units distinct from ICUs. Then, we show how the ICU culture can be measured, and summarise research on the culture-performance relationship in ICUs.
\end{abstract}

For the World Health Organization, the definition of health is a state of complete physical, mental and social well-being and not merely the absence of disease or infirmity [1]. As a consequence, the scope of quality of care has broadened and should consider not only mortality but also other dimensions of performance, such as satisfaction of the patient and his/her family, longterm quality of life and functional recovery. Moreover, financial constraints on ICUs are increasing, justifying integrating this dimension in the global assessment of ICU performance, but with potential drawbacks and ethical concerns $[2,3]$. This raises the issue of rationing health care $[4,5]$, with potential conflict arising in teams if values are not shared and consensus is not reached.

Intensive care medicine is expanding in all western countries [6] but with large heterogeneity in the number of beds [7] as well as in organisation and management. It includes several specificities mostly related to uncertainty (unplanned activities), urgent situations, stressful environments and high mortality rate. Groups of people are involved directly or indirectly in patient care (physicians, nurses, nurse's aids, physiotherapists, clerks, and janitors), and these multidisciplinary ICU teams are at risk of making errors resulting from cooperation-communication failures. As a matter of fact, several studies have

${ }^{*}$ Correspondence: Bertrand.guidet@sat.aphp.fr; Vicente.glez-roma@uv.es ${ }^{3}$ Assistance Publique - Hôpitaux de Paris, Hôpital Saint-Antoine, service de réanimation médicale, Paris, F-75012, France

${ }^{4}$ Idocal, University of Valencia, Av. Blasco Ibáñez, 21, 46010-Valencia, Spain Full list of author information is available at the end of the article documented that iatrogenic events are frequently reported in ICUs $[8,9]$ and that a good management and safety culture is able to reduce the rate of medical errors [10].

In order to reduce the number of adverse events and to improve patient outcome globally, a climate and culture of safety and quality have to be implemented in ICUs. Several factors hinder this approach, however, such as dictatorial behaviour, lack of mutual respect, and fears of being stigmatised. New technology (for example, fancy ventilator or dialysis machines) has little chance of improving patient outcome if a team-oriented culture is not promoted in ICUs.

This collaborative article is structured as follows. First, we define the concepts of work unit climate and culture. Second, we briefly summarise what we have learnt about the climate-performance relationship in work units from the field of work and organisational psychology. Third, we focus on how unit culture can be measured in ICUs and summarise research on the aforementioned relationship in ICUs. Finally, we present a number of conclusions.

\section{ICU climate and culture}

Organisational theory and research have shown that work units' climate and culture exert important influences on work units' outcomes, such as unit performance $[11,12]$. Climate refers to work unit members' shared perceptions about the policies, procedures, and practices that are implemented in their work environment. According to their content, these shared perceptions can be clustered in homogeneous groups called climate facets (such as service climate or safety climate). Depending on the work unit's activity, some climate facets can have more strategic importance than others; for instance, a high service climate in a hospital is crucial for achieving high levels of patient satisfaction. Culture refers to a system of shared values, assumptions, and underlying beliefs that influences the way of doing things in work units [13]. According to the values, assumptions, and underlying beliefs that characterise a given unit, distinct types of culture can be specified (for example, clan culture, market culture, constructive culture).

Climate and culture are two interrelated concepts. The elements that form a unit's culture determine the policies and procedures supported by managers [14]. For instance, in a hospital where providing a high quality 
service is an important and shared value, managers provide training to health professionals about how to interact with patients and their relatives. Once those policies and procedures are translated into implemented practices and are socially interpreted by unit members, climate perceptions develop and emerge. In the aforementioned hospital, the participation of health professionals in training courses aimed at increasing service quality through the development of better social skills should lead to a high level of service climate. Thus, a work unit's climate also provides a way to learn about its culture [15].

\section{Unit climate and performance}

Work unit climate provides a shared representation of the work environment that enables team members to assign shared meaning to events that are important for the unit, and to determine the actions that will lead to desired outcomes $[16,17]$. These ideas have led researchers to posit that unit climate is related to unit performance, which is one of these desired outcomes.

There is some empirical evidence supporting the relationship between unit climate and different indicators of unit performance across different types of work units and involving different climate facets [11,18-20]. For instance, Schneider and colleagues [20], in a sample of bank branches, found that service climate positively predicted subsequent customers' assessments of service quality. Zohar [18] found in a sample of work groups from a manufacturing company that safety climate was negatively related to work groups' injury rates. Finally, González-Romá and colleagues [21] found in a longitudinal study using a sample of bank branches that support climate (the extent to which policies, procedures, and practices foster support from the organisation and their managers) was positively related to branch members' and branch managers' ratings of unit performance over time.

\section{The moderator role of climate strength}

Recent research has shown that the relationship between work unit climate and unit outcomes is moderated by climate strength (that is, the degree of within-unit agreement of employees' climate perceptions). This research assumes that a unit's climate can be characterised not only by the average of unit members' climate scores (that is, the climate level) but that climate strength has to be taken into account as well. In several studies [19,21-24], the moderator influence of climate strength was in the expected direction - climate strength fostered the relationship between work units' climate and outcome variables - so that when climate strength was high, the relationship was enhanced, whereas when climate strength was low, the relationship was weakened.
For instance, González-Romá and colleagues [22], in a sample of public health service units, found that climate strength moderated the positive relationship between innovation climate (the extent to which policies, procedures, and practices foster new ideas about work and their implementation) and unit satisfaction and commitment. Schneider and colleagues [23], in a sample of bank branches, found that climate strength moderated the impact of branch service climate on customer perceptions of service quality. Finally, in the aforementioned study carried out by González-Romá and colleagues [21], climate strength moderated the relationship between the climate facets of support and innovation on the one hand and subjective and objective (financial) indicators of unit performance on the other. Interestingly, the relationship between branch climate and financial performance was observed only in branches with high climate strength. This result suggests that in order for unit climate to be related to subsequent financial unit performance, unit climate must be strong (that is, there must be a high degree of within-unit agreement of employees' climate perceptions).

Theoretically, the moderator influence of climate strength on the team climate-team performance relationship has been based on Mischel's [25] concept of situational strength. Situational strength refers to the degree of ambiguity present in the context. Strong situations lead people to interpret events in a similar way, induce uniform expectancies regarding the most appropriate behaviour, and provide adequate incentives for the performance of that behaviour. In strong situations, behavioural variability will be small $[25,26]$. Weak situations are not uniformly interpreted, do not produce uniform expectancies regarding the desired behaviour, and do not provide sufficient incentives for its performance [25]. In weak situations, behavioural variability will be large $[25,26]$. Therefore, unit climates with high climate strength (strong climates) foster uniform and consistent performance-related behaviours, whereas in units with a weak climate (low climate strength), the variability of performance-related behaviours is larger. This affects the predictability of team performance such that it will be more predictable in strong climate conditions than in weak ones [27]. Low climate strength means that idiosyncratic work unit perceptions develop within a unit, which produce wide variability in individual behaviours, diminishing the relationship between unit climate and unit performance [14]. Moreover, in work units where functional interdependence is important, coordinated action is required to carry out the unit's tasks and achieve the unit's goals. This coordinated action is facilitated when unit members agree on the meaning of important elements (policies, procedures, and practices) of their work environment (that is, when climate strength is high). 


\section{The antecedents of climate strength}

If climate strength enhances the relationship between unit climate and unit performance, it makes sense to identify the antecedents of climate strength. Several studies have underlined the role of the work unit leader in this regard. Through leader-member interaction and communication, leaders can contribute to fostering within-unit agreement regarding climate perceptions (that is, climate strength). In these interactions, leaders may inform unit members about policies, procedures and practices. Considering that leaders may serve as interpretive filters of relevant work unit events, features, and processes [28], it is reasonable to expect that leaders, by means of this communication behaviour, will shape unit members' perceptions of the unit, promoting climate strength. Empirical research supports this relationship. González-Romá and colleagues [22] found a positive relationship between unit leaders' informing behaviour and climate strength in a sample of public health service units.

Other aspects of unit leaders' behaviour also influence climate strength. Zohar and Luria [29] observed that variability in leaders' behavioural patterns was negatively related to safety climate strength, whereas simplicity of leaders' behavioural patterns was positively related. Finally, Naumann and Bennet [30] found that visibility of work units' supervisors was positively related to climate strength. These empirical findings show that unit leaders play a crucial role in shaping the climate of their work units.

The relationships between the level and strength of work unit climate and a number of antecedents (for example, leaders' behaviour) and consequences (for example, unit performance) have been documented in distinct types of work units (for example, bank branches, health units, manufacturing work groups); however, there is a scarcity of research examining these relationships in ICU samples. The high degree of interdependence that these units show suggests that the aforementioned relationships should also operate in ICU samples.

\section{Analytical framework and tools to assess ICU culture and organisation}

The concept developed in industry builds a strong background for a proof of concept but does not necessarily translate to the ICU environment; the working hypothesis is thus largely speculative.

\section{Framework}

Safety culture might be defined as the product of individual and group values, attitudes, perceptions, competencies, and patterns of behaviour that determine the commitment to, and the style and proficiency of, an organisation's health and safety management. Culture and climate are measured at the individual level, but the two concepts are operationalised at the group unit level. Culture refers to shared values and climate to shared perceptions. The definitions used are summarised in Table 1.

Figure 1 summarises the relationship between all these factors. It must be stressed that although it is well documented in other fields (see above), the relative contribution of each factor to the final outcome is unknown in ICU samples. More importantly, very few data link an intervention aiming at improving one of the factors and performance.

The model has been adapted over a 20-year period for the ICU environment. The first study by Shortell and colleagues [31] established the basic framework for the culture-outcome relationship in ICUs. It was used by Miranda and colleagues in the EURICUS (European ICU Studies) project [32], then promoted by the Society of Critical Care Medicine in the USA [33], refined in our own study [34], and integrated in a global perspective of team performance for ICUs [35]. It must be stressed that other factors contribute to performance in ICUs, such as equipment, external control, incentives, and public release of performance indicators.

The multiplicity of factors and the paucity of data in ICUs explain that the presented model/framework is not fully validated. As discussed later, however, a shared climate on a strategic facet (for example, service, safety) and a team-oriented culture are able to improve organisation and contribute to better well-being of staff members. As a consequence, it is desirable to implement a teamoriented culture. To do so, a first step for ICU directors is to assess the current culture of their units using a validated questionnaire encompassing all dimensions of culture and organisation.

\section{Questionnaires}

Many questionnaires have been developed in order to assess culture and team processes in ICUs. The first was developed by Shortell and colleagues [31], whose study included 42 ICUs and over 1,700 respondents and provided evidence for the reliability and validity of a comprehensive set of measures related to leadership, organisational culture, communication, coordination, problem solving-conflict management and team cohesiveness. The data also supported the appropriateness of aggregating individual respondent data to the unit level.

The EURICUS-I project expanded the Shortell questionnaire and included 89 ICUs in 12 European countries [32]. The questionnaires of Shortell and colleagues and Miranda and colleagues were not fully validated and did not consider some important aspects of management. Other questionnaires are available, such as Safety Attitudes Questionnaire-ICU [36], which is derived from 
Table 1. Definition of items used in the manuscript

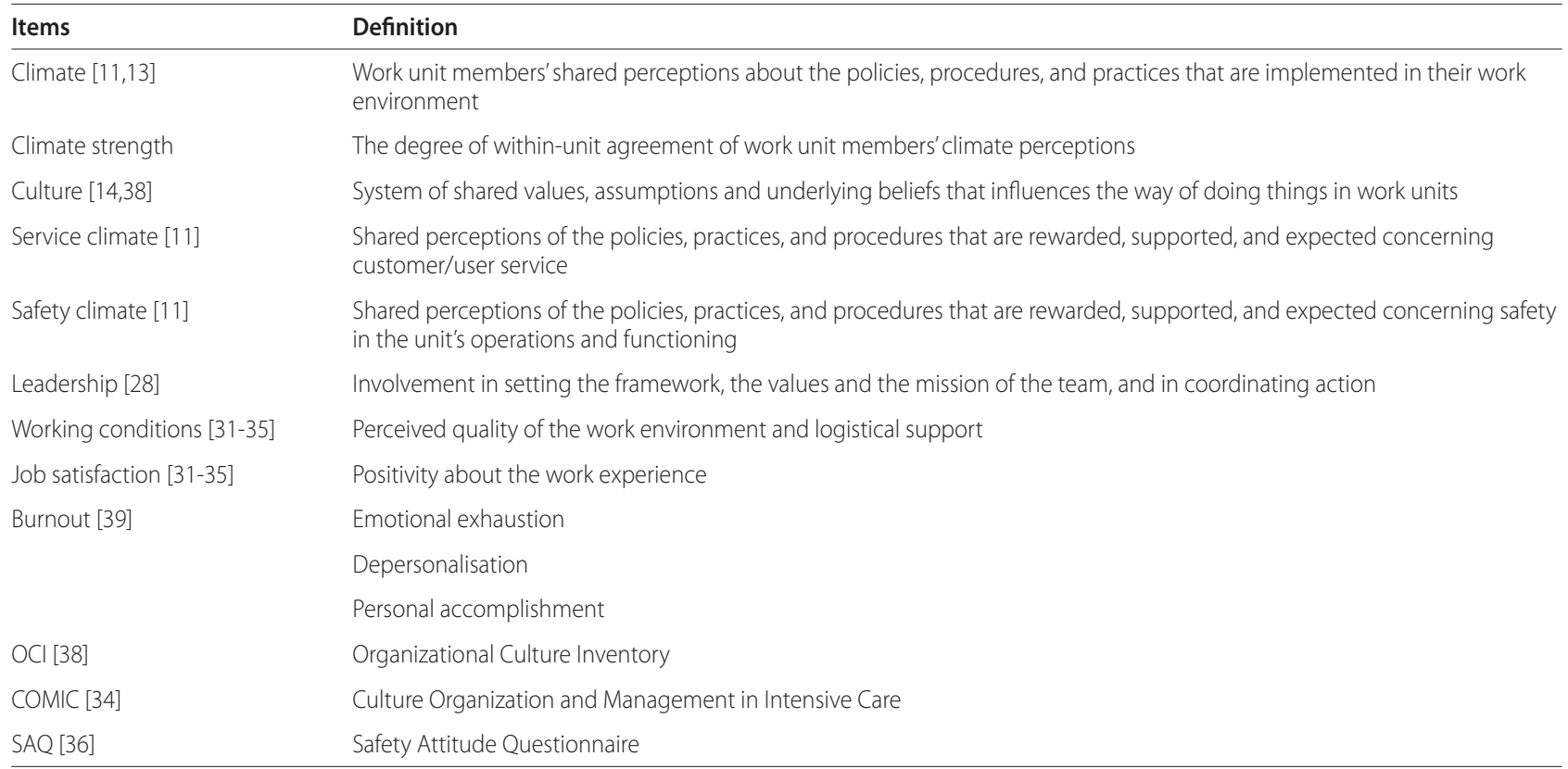

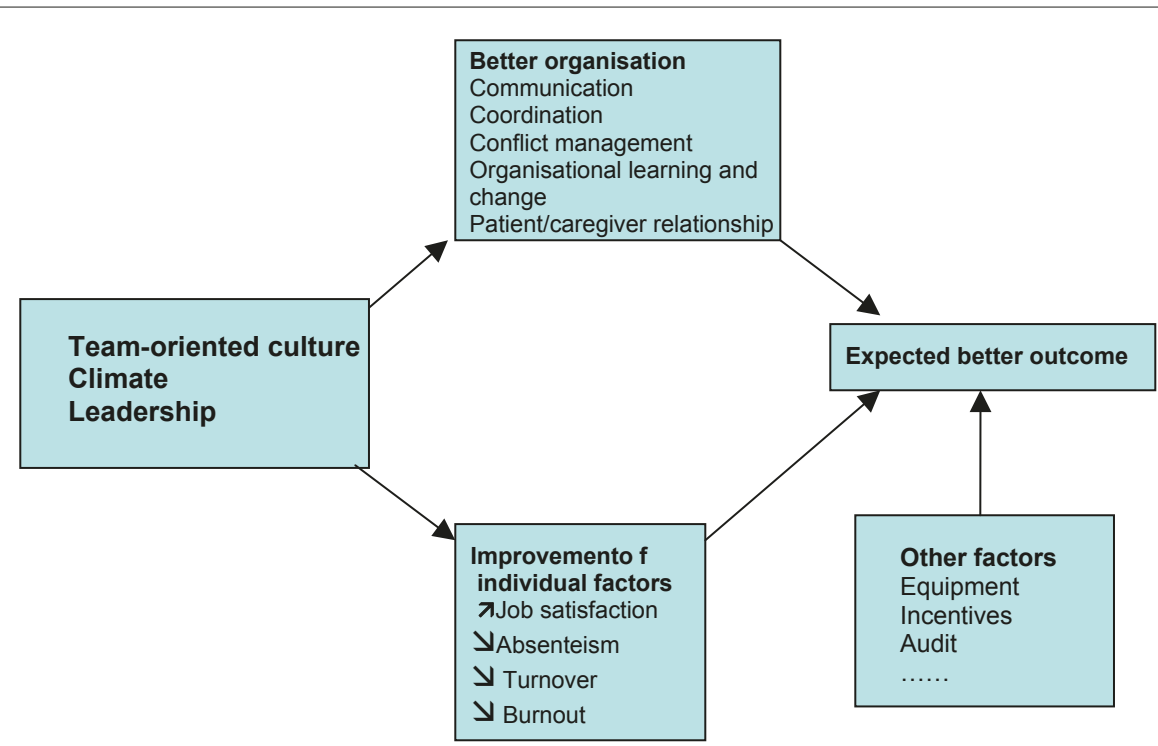

Figure 1. Analytical framework. Leadership together with a safety climate and a team-oriented culture are able to improve organisation and improve individual well being, both potentially contributing to overall performance. Strong evidence links climate/culture and organisational performance. Several other factors contribute to performance assessed through outcome variables. The direct demonstration that a specific intervention aiming at improving one these different factors is able to improve final outcome is still lacking in ICUs.

the cockpit management attitude questionnaire [37]. We developed a questionnaire named COMIC (for Culture, Organisation and Management in Intensive Care') [34] that combines a set of independent variables that include cultural, managerial, well-being, and unit effectiveness dimensions in order to give an integrative overview of the 'organisation' variable.
The COMIC questionnaire provides a 13-item measure of ICU culture based on the Organisational Culture Inventory [38]. A team-satisfaction-oriented culture is expected to be positively correlated with more effective managerial practices, whereas people-security and tasksecurity cultures would be negatively associated with the development of effective managerial practices [38]. 
Relations with patients and family members should be assessed together with individual well-being with a specific focus on burnout, which is measured with the Maslach Burnout Inventory [39].

\section{ICU culture/climate and performance}

Studies that have examined the relationship between culture/climate and ICU performance

Based on data collected from 17,440 patients across 42 ICUs, Shortell and colleagues [40] were able to reveal that caregiver interaction comprising the culture, leadership, coordination, communication, and conflict management abilities of the unit is significantly associated with lower risk-adjusted length of stay, lower nurse turnover, higher evaluated technical quality of care, and greater evaluated ability to meet family member needs. In another study from the same group [41], 3,045 eligible coronary artery bypass graft surgery patients were analysed. Total quality management was implemented and organisational culture was measured. A two- to fourfold difference in all major clinical coronary artery bypass graft surgery care endpoints was observed among the 16 hospitals, but little of this variation was associated with total quality management or organisational culture. High total quality management was associated with more satisfaction with nursing care but with a longer length of stay.

In the study of Huang and colleagues [42], culture scores were low to moderate. After adjustment for patient, hospital and ICU characteristics, for every $10 \%$ decrease in ICU perceptions of management percentpositive score, the odds ratio for hospital mortality was 1.24. However, other dimensions of safety had no impact on mortality (stress recognition, job satisfaction, working conditions, team climate). For every $10 \%$ decrease in ICU safety climate percent-positive score, the length of stay increased $15 \%$.

We analyzed the answers to the COMIC questionnaire of 1,000 ICU personnel from 26 ICUs located in the Paris area (750 nurses, 26 head nurses, 168 physicians and 56 medical secretaries) [43]. A team-satisfaction-oriented culture correlated positively with all measures of effective managerial practices, while task-security- and peoplesecurity-oriented cultures correlated negatively with effective managerial practices. Team-satisfaction-oriented culture was positively associated with all measures of individual well-being. Overall, there was a positive relationship between team-satisfaction-oriented culture and good managerial practices on the one hand and between the absence (or low level) of burnout and good job satisfaction on the other hand. Organisational performance was assessed through a composite score related to five dimensions: coordination and adaptation to uncertainty; communication; conflict management; organisational change and organisational learning; and skills developed in relationship with patients and their families. The multilevel analysis assessing the respective contribution of structural, contextual and individual factors to the organisational score showed that only $9.5 \%$ of the variation was due to ICU-level factors. At the individual level, the significant variables were lack of burnout, satisfaction to work, and older mean age, while at the ICU level a high physician and nurse-to-bed ratio and an important workload per day were significant. All these factors were positively correlated with organisational performance. If we consider the interactions between burnout, organisational performance, and high workload per day, the results suggest two interpretations: that a high level of organisational performance supports a high workload and prevents burnout; and that a high level of organisational performance supports a high workload without thinking about burnout.

In another study, the authors were unable to find an association between organisational culture, team climate, or preventive quality management at the ward level and the prevalence of nosocomial pressure ulcers [44].

Sexton and colleagues [45] studied the impact of implementing a unit-based safety program in 71 ICUs to improve unit safety culture, such as teamwork and safety climate. The safety climate was assessed with the Safety Attitude Questionnaire (SAQ). Overall, mean safety climate scores improved, with scores higher in faithbased ICUs and smaller hospitals. However, the conclusion of the work was 'research linking improved climate and clinical outcomes is a critical next step.

\section{Difficulties in demonstrating an impact on patient outcome}

A recent review concluded that even if some evidence existed, articulating the nature of the relationship between culture/climate and ICU performance was difficult and stated that 'In particular, stronger methodological definitions and operationalizations of both culture and outcomes were recommended' [46].

The culture-outcome relationship is very difficult to assess for several reasons: besides culture/climate, several factors (case mix, environment, financial constraints) might contribute to the final outcome (that is, mortality, morbidity, length of stay, and so on). There is a general concern about the best performance indicator for ICUs; no validated composite performance score is available that enables a single dependant variable to be used in a statistical model. Moreover, most studies lack statistical power to detect an impact of an intervention on outcomes since the studies use the ICU and not the individual patients as the level of analysis.

Recommendations for designing future studies might be to use validated tools, to include a large number of 
ICUs, to assess a single composite performance indicator, to compute multilevel analysis, and to define precisely the intervention aimed at improving culture/climate.

\section{Conclusion}

Research carried out in different types of work units shows that unit climate is an important antecedent of unit performance [11]. This empirical evidence suggests that climate in ICUs can also have an important influence on ICU outcomes. Research aimed at testing this hypothesis in samples of ICUs is needed. Research carried out on the culture-performance relationship in ICUs shows that unit culture impacts on relevant performance indicators (for example, length of stay). Studies are still scarce, however, and more investigations are needed to ascertain the scope and importance of this influence. The role of the work unit leader in shaping unit climate and culture is critical. Therefore, training ICU leaders can be an effective strategy to build an adequate unit climate and culture in such a way that ICU performance is maximised. A global approach is necessary with probably more involvement of relatives [47].

This article is part of a series on Healthcare Delivery, edited by Dr Andre Amaral and Dr Gordon Rubenfeld.

\section{Abbreviations}

COMIC, Culture, Organisation and Management in Intensive Care; EURICUS, European ICU Studies.

\section{Competing interests}

The authors declare that they have no competing interests.

\section{Author details}

'Inserm, Unité de Recherche en Épidémiologie Systèmes d'Information et Modélisation (U707), Paris, F-75012, France. 2UPMC Univ Paris 06, France. ${ }^{3}$ Assistance Publique - Hôpitaux de Paris, Hôpital Saint-Antoine, service de réanimation médicale, Paris, F-75012, France. ${ }^{4}$ Idocal, University of Valencia, Av. Blasco Ibáñez, 21, 46010-Valencia, Spain.

Published: 16 November 2011

\section{References}

1. World Health Organization: Preamble to the Constitution of the World Health Organization as adopted by the International Health Conference, New York, 19-22 June, 1946; signed on 22 July 1946 by the representatives of 61 States (Official Records of the World Health Organization, no. 2, p. 100) and entered into force on 7 April 1948.

2. Neumann $P$, Weinstein M: Legislating against use of cost-effectiveness information. N Engl J Med 2010, 363:1495-1497.

3. Luce $J M$, White DB: The pressure to withhold or withdraw life-sustaining therapy from critically ill patients in the United States. Am J Respir Crit Care Med 2007, 175:1104.

4. Sinuff T, Kahnamoui K, Cook DJ, Luce JM, Levy MM: Values, Ethics \& Rationing in Critical Care (VERICC) Task Force. Crit Care Med 2004, 32:1588-1597.

5. Truog RD, Brock DW, Cook DJ, Danis M, Luce JM, Rubenfeld GD, Levy MM; for the Task Force on Values, Ethics, and Rationing in Critical Care (VERICC): Rationing in the intensive care unit. Crit Care Med 2006, 34:958-963.

6. Adhikari NK, Fowler RA, Bhagwanjee S, Rubenfeld GD: Critical care and the global burden of critical illness in adults. Lancet 2010, 376:1339-1446.

7. Wunsch $H$, Angus DC, Harrison DA, Collange O, Fowler R, Hoste EA, de Keizer NF, Kersten A, Linde-Zwirble WT, Sandiumenge A, Rowan KM: Variation in critical care services across North America and Western Europe. Crit Care Med 2008, 36:2787-2793.

8. Valentin A, Capuzzo M, Guidet B, Moreno R, Dolanski L, Bauer P, Metnitz P: Patient safety in intensive care: results from the multinational Sentinel Events Evaluation (SEE) study. Intensive Care Med 2006, 32:1591-1598.

9. Valentin A, Capuzzo M, Guidet B, Moreno R, Metnitz B, Bauer P, Metnitz P: Research Group on Quality Improvement of the European Society of Intensive Care Medicine (ESICM); Errors in the administration of parenteral drugs - an urgent safety issue in intensive care units. Results from a multinational, prospective study. Sentinel Events Evaluation (SEE) Study Investigators. BMJ 2009, 338:b814.

10. Festa MS: Clinical leadership in hospital care: leadership and teamwork skills are as important as clinical management skills. BMJ 2005, 331:161-162.

11. Kozlowski SWJ, Ilgen, DI: Enhancing the effectiveness of work groups and teams. Psych Sci 2006, 7:77-124.

12. Gillespie MA, Denison DR, Haaland S, Smerek R, Neale WS: Linking organizational culture and customer satisfaction: Results from two companies in different industries. Eur J Work Organizational Psychol 2008, 17:112-132.

13. Verbeke W, Volgering M, Hessels M: Exploring the conceptual expansion within the field of organizational behavior: Organizational climate and organizational culture. J Management Studies 1998, 35:303-329.

14. Ostroff C, Kinicki AJ, Tamkins MM: Organizational culture and climate. In Handbook of Psychology. Volume 12: Industrial and organizational psychology. Edited by Borman WC, Ilgen DI, Klimoski RJ. Hoboken, NJ: John Wiley \& Sons; 2003:565-594.

15. Zohar D, Hofmann DA: Organizational culture and climate. In Oxford Handbook of Industrial and Organizational Psychology. Edited by Kozlowski SWJ. Oxford University Press; in press.

16. James LR, Choi CC, Ko CE, McNeil PK, Minton MK, Wright MA, Kim K: Organizational and psychological climate: A review of theory and research. Eur J Work Organizational Psychol 2008, 17:5-32.

17. Parker CP, Baltes BB, Young SA, Huff JW, Altmann RA, Lacost HA, Roberts JE: Relationships between psychological climate perceptions and work outcomes: a meta-analytic review. J Organizational Behav 2003, 24:389-416.

18. Zohar D: A group-level model of safety climate: Testing the effect of group climate on microaccidents in manufacturing jobs. J App/ Psychol 2000, 85:587-596.

19. Colquitt JA, Noe RA, Jackson CL: Justice in teams: antecedents and consequences of procedural justice climate in teams. Personnel Psychol 2002, 55:83-109.

20. Schneider B, White SS, Paul, MC: Linking service climate and customer perceptions of service quality: test of a causal model. J Appl Psychol 1998, 83:150-163.

21. González-Romá V, Fortes-Ferreira L, Peiró JM: Team climate, climate strength and team performance. A longitudinal study. J Occupational Organizational Psychol 2009, 82:511-536.

22. González-Romá V, Peiró JM, Tordera N: An examination of the antecedents and moderator influences of climate strength. J Appl Psychol 2002, 87:465-473.

23. Schneider B, Salvaggio AM, Subirats M: Climate strength: a new direction for climate research. J Appl Psychol 2002, 87:220-229.

24. Moliner C, Martínez-Tur V, Peiró JM, Cropanzano R: Relationships between organizational justice and burnout at the work-unit level. Int J Stress Management 2005, 12:99-116.

25. Mischel W: Toward a cognitive social learning reconceptualization of personality. Psychol Rev 1973, 80:252-283.

26. Ostroff C, Bowen DE: Moving HR to a higher level: HR practices and organizational effectiveness. In Multilevel Theory, Research, and Methods in Organizations. Edited by Klein KJ, Kozlowski SWJ. San Francisco: Jossey-Bass; 2000:211-266.

27. Lindell MK, Brandt CJ: Climate quality and climate consensus as mediators of the relationship between organizational antecedents and outcomes. J Appl Psychol 2000, 85:331-348.

28. Kozlowski SWJ, Doherty ML: Integration of climate and leadership: examination of a neglected issue. J App/ Psychol 1989, 74:546-553.

29. Zohar D, Luria G: Climate as a social-cognitive construction of supervisory safety practices: scripts as a proxy of behavior patterns. J Appl Psychol 2004, 89:322-333

30. Naumann SE, Bennet N: A case for procedural justice: development and 
test of a multilevel model. Acad Management J 2000, 43:881-889.

31. Shortell SM, Rousseau DM, Gillies RR, Wagner DP, Draper EA, Knaus WA, Duffy J: Organizational Assessment in Intensive Care Units (ICUS): construct development, reliability, and validity of the ICU nurse-physician questionnaire. Med Care 1991, 29:709-723.

32. Miranda DR, Ryan DW, Schaufeli WB, Fidler V: Organization and Management of Intensive Care: a Prospective Study in 12 European Countries. Update in Intensive Care and Emergency Medicine. Berlin: Springer-Verlag; 1997.

33. Curtis JR, Cook DJ, Wall RJ, Angus DC, Bion J, Kacmarek R, Kane-Gill SL, Kirchhoff KT, Levy M, Mitchell PH, Moreno R, Pronovost P, Puntillo K: Intensive care unit quality improvement: A "how-to" guide for the interdisciplinary team. Crit Care Med 2006, 24:211-218.

34. Minvielle E, Dervaux B, Retbi A, Aegerter P, Jars-Guincestre MC, Tenaillon A Guidet B: Culture organization and management in Intensive Care (COMIC). Part 1 Construction and validation of a multidimensional questionnaire. J Crit Care 2005, 20:126-138,

35. Reader TW, Flin R, Mearns K, Cuthbertson BH: Developing a team performance framework for the intensive care unit. Crit Care Med 2009, 37:1787-1793.

36. Sexton JB, Helmereich RL, Neilands TB, Rowan K, Vella K, Boyden J, Roberts PR, Thomas EJ: The safety attitude questionnaire: psychometric properties, benchmarking data and emerging research. BMC Health Serv Res 2006, 6:44.

37. Helmreich RL: Cockpit management attitudes. Hum Factors 1984, 26:583-589.

38. Cooke RA, Szumal JL: Measuring beliefs and shared behavioural expectations in Organizations: the reliability and validity of the Organizational Culture Inventory. Psychol Rep 1993, 72:1299-1330

39. Maslach C, Jackson SE, Leiter MP: The Maslach Burnout Inventory. 3rd edition. Palo Alto, CA: Consulting Psychologists Press, 1996.

40. Shortell SM, Zimmerman JE, Rousseau DM, Gillies RR, Wagner DP, Draper EA Knaus WA, Duffy J: The performance of intensive care units: does good management make a difference. Med Care 1994, 32:508-525

41. Shortell SM, Jones RH, Rademaker AW, Gillies RR, Dranove DS, Hughes EF, Budetti PP, Reynolds KS, Huang CF: Assessing the impact of total quality management and organizational culture on multiple outcomes of care for coronary artery bypass graft surgery patients. Med Care 2000, 38:207-217.

42. Huang DT, Clermont G, Kong L, Weissfeld LA, Sexton JB, Rowan KM, Angus DC: Intensive care unit safety culture and outcomes: a US multicenter study. Int J Quality Health Care 2010, 22:151-161.

43. Minvielle E, Aegerter P, Dervaux B, Boumendil A, Retbi A, Jars-Guincestre MC Guidet B: Assessing organizational performance in ICU's: A French experience. J Crit Care 2008, 23:236-244.

44. Bosch M, Halfens RJ, van der Weijden T, Wensing M, Akkermans R, Grol R: Organizational culture, team climate, and quality management is an important patient safety issue: nosocomial pressure ulcers. Worldviews Evid Based Nurs 2011, 8:4-14.

45. Sexton JB, Berenholtz SM, Goeschel CA, Watson SR, Holzmueller CG, Thompson DA, Hyzy RC, Marsteller JA, Schumacher K, Pronovost PJ: Assessing and improving safety climate in a large cohort of intensive care units. Crit Care Med 2011, 39:934-939.

46. Scott T, Mannion R, Marshall M, Davies H: Does organisational culture influence health care performance? A review of the evidence. J Health Serv Res Policy 2003, 8:105-117.

47. Carlet J, Garrouste-Orgeas M, Dumay MF, Diaw F, Guidet B, Timsit JF, Misset B: Managing intensive care units: Make LOVE not war! J Crit Care 2010, 25:359. e9-359.e12.

doi:10.1186/cc10361

Cite this article as: Guidet B, González-Romá V: Climate and cultural aspects in intensive care units. Critical Care 2011, 15:312. 